\title{
Validation of the intellectual capital scale of nursing services
}

\author{
João Soares-Faria*1, Helena Santos-Rodrigues², Beatriz Araújo ${ }^{1}$, Cláudia Valente ${ }^{3}$ \\ ${ }^{1}$ Institute of Health Sciences of the Catholic University of Portugal, Center for Interdisciplinary Research in Health, Porto, \\ Portugal \\ ${ }^{2}$ Management and Business Management, Polytechnic Institute of Viana do Castelo, ESTG, Portugal \\ ${ }^{3}$ Design and Humanities at the Polytechnic Institute of Viana do Castelo, Portugal
}

Received: January 10, 2018

DOI: $10.5430 /$ jha.v7n2p50
Accepted: March 24, 2018

Online Published: April 8, 2018

\begin{abstract}
Objective: Nursing services are considered strategic in the functioning of health organizations, therefore the study of intellectual capital (human capital, structural capital, relational capital of nursing services) in innovation as a contribution to decision policies, practice and research. The main focus is to promote critical thinking on the condition of nursing services in an innovative perspective. This study aims to adapt and validate the psychometric properties of the Questionnaire of Intellectual Capital and Innovative Capacity (already used in business management, automobile) and apply it to the Nursing Services (QICICNS).

Methods: A cross-sectional and quantitative study was carried out on a sample of 1,388 Portuguese nurses enrolled in the Nurses' Order. For the analysis of the psychometric properties of the instrument we used the factorial analysis of main components with varimax rotation of the scale items and the calculation of the Cronbach Alpha coefficient.

Results: The QICICNS analysis revealed good internal consistency (global scale $=0.95$, constructs between 0.83 and 0.97 ) and good quality of the items $(\mathrm{KMO}=0.95)$, with four factors being extracted: human capital, relational capital, structural capital and innovation.

Conclusions: The positive indices of internal consistency and the sensitivity of this questionnaire show the validity of the reliable and robust data collection instrument in the studied context. Implications for nursing management: QICICNS, due to its multifaceted nature, can be a management tool in the decision making support by nursing managers. The characteristics of each intellectual capital construct may influence the management of services and future investigations.
\end{abstract}

Key Words: Adaptation, Validation, Intellectual capital, Innovation, Nursing

\section{INTRODUCTION}

In the study of relevance of intellectual capital in the innovation of services in Portuguese health organizations, it is essential to consider the nursing services. Given the broad nature of nursing interventions, intend to adapt and validate the Santos-Rodrigues, Figueroa-Dorrego and Jardón-Fernández (2008), ${ }^{[1]}$ questionnaire for the nursing area, which was re- named QICICNS. These authors consider that this questionnaire was built with strategic issues of intellectual capital of services, therefore adjustable to nursing services. The aim of this questionnaire is to extend it to any organizational management, which includes health services, particularly nursing services, human factors, relational factors and structural factors.

\footnotetext{
${ }^{*}$ Correspondence: João Soares-Faria; Email: Jfariaenf@hotmail.com; Address: Institute of Health Sciences of the Catholic University of Portugal, Center for Interdisciplinary Research in Health, Porto, Portugal.
} 


\section{Priors}

Intellectual capital (CI) contemplates "intangible asset" described it with categories or examples. As the stock of nursing knowledge, available in an organization has small variations in terms, definitions and discipline, the researchers accept the tripartite definition of IC, which consists of capital, (1) human that refers to the knowledge, skills and experiences used by individuals, (2) structural/organizational refers to institutionalized knowledge and coded experience stored in databases, procedures, routines and other organizational structures; (3) relational reporting to knowledge incorporated and derived from networks of internal and external relations to the organization. The IC is distributed in three different ways: individuals; Organizational structures, processes and systems and relationships and networks. ${ }^{[2]}$

In the last decades, studies have emerged based on the improvement of health organizations' performance, reinforcing the possible effect of knowledge. ${ }^{[3]}$ Some studies describe the different stages of CI research in organizations and conclude from the need to define concepts within the CI components through the knowledge assets of organizations.

In the nursing area, the IC theory was developed based on the high costs of services, and the need to understand the influence of his knowledge, skills and experiences on the service rendered, and organizational results. ${ }^{[4]}$ Thus, it is suggested that the nursing knowledge available in health organizations is influenced by variables of the work environment which influence the care to patients and the health unit. This theory of medium-range nursing has derived from IC theory to make it relevant and enforceable to continuous professional development. Covell ${ }^{[4]}$ conducted a study based on two components of IC: human capital (nurses' ratio and training), structural capital (protocols for fall prevention, error prevention and infection control, guidelines and care plans), and in the way, they are associated with the quality of care provided, the ratio of professionals and the level of professional retention. The author concluded that the medium-range IC theory should be tested in different health systems and in different settings and countries to determine their effectiveness in guiding research. This theory is a way for nurse managers to develop the IC of nursing services. The nursing managers need to acquire a thorough knowledge of models and theories of administration and management in nursing. ${ }^{[5]}$

In a study on the influence of IC in the innovative capacity of a hospital, the influence of health professionals on the innovative capacity of a hospital, supported by the triad of intellectual capital (human, structural and relational), concludes that all these components influenced, in a different way, the innovative capacity of the hospital. ${ }^{[6]}$

Published by Sciedu Press
Assessment by nurse research and management experts, seek to find new ways of doing so, seek innovation as an ally in improving services and reducing costs. The concept of innovation shows a tendency to undertake and support new ideas, experiences and creative processes, from which new products, services or technological processes can result. All creation process that becomes useful and effective favors the innovation in the health area, justifying by itself, the interest in studies on innovation in health organizations. ${ }^{[7]}$

The Portuguese health units are public management entities and their permanent supervision requires that management instruments as well as new ways of achieving the objectives outlined can be found. There must be awareness in health spending and on the impact of knowledge on the quality of care provided to the user, making it necessary to affect the relationship between their knowledge and nursing practice. ${ }^{[8]}$ Assessment by nurse research and management experts, are considered essential in the changes of health organizations, showing interest in understanding the impact of nursing knowledge on care to the users. ${ }^{[9]}$ In this context, we intend to address the influence of IC in innovation, adapting and validating QICICNS on a sample of Portuguese nurses.

\section{METHODS}

A cross-sectional quantitative study was carried out in order to adapt the questionnaire to the Portuguese nursing services. Assessment by nurse research and management experts; semantic validation (Portuguese) and content that fit the organizational context of the health services, with the final goal of excluding indicators that could be misunderstood. Content changes were made based on the observations and suggestions of those experts. The pre-test was then performed on a sample of 20 nurses, to assess the items' comprehension by interviewees.

\subsection{Data collection}

The sample involved 1,388 Portuguese nurses enrolled in the Nurses' Order. QICICNS is a self-report instrument, with information on the components of intellectual capital: human capital, relational capital and structural capital, as well as the type of innovation or adopted. This questionnaire consists of four constructs (Innovation, Structural Capital, Relational Capital, and Human Capital) and a total of 33 items. Each item is answered on a Likert scale, with 5 response options: (1) Nothing agrees; (2) I do not agree in part; (3) Indifferent; (4) Partially agree; and, at last (5) Strongly agree.

\subsection{Procedures}

The final version of QICICNS was approved by the Ethics Committee of the Health Sciences Institute of the Catholic 
University of Portugal and gave the IRB approval with ID $n^{0} 15 / 2015$. The online questionnaire was built based on the Qualtrics Research Suite ${ }^{\circledR}$ platform, with the options of not indexing the same in search engines and with exclusive access through a single link. In this questionnaire the response takes about 5 minutes, no data was collected that could identify the respondent or the place of data collection. Subsequently, the request for sending the link to the questionnaire to all Portuguese nurses, with an electronic address, enrolled in the Nurses' Order, was done to the Nurses' Order.

The data collection period ran from February 19 to March 20, 2016. Anonymity and confidentiality were guaranteed, and the questionnaire response was voluntary.

All data were analyzed from the Statistical Package for Social Sciences (SPSS) for Windows, version 22.0. To perform the psychometric evaluation of QICICNS in nurses, we proceeded to the exploratory factorial analysis of the items in main components, with orthogonal rotation by the varimax method, to verify the construct validity and determination of the Cronbach Alpha coefficient to evaluate the internal consistency of the total scale and constructs.

\section{RESULTS}

In a sample of 1,388 nurses, $73.8 \%$ are female, with an average age of 38.8 years and a standard deviation of 9.87 years. Its academic profile is mainly concentrated in the undergraduate degree $(100.0 \%$ ), with $25.4 \%$ of respondents having a master's degree, $2.2 \%$ having a doctoral degree, and $21.8 \%$ indicating that they had Specialization in nursing. Those nurses perform functions in: hospital health care units (60.5\%); Primary health care units $(22.5 \%)$; Integrated care units (5.3\%); other health units (11.7\%). Most nurses have an individual contract of indefinite time term (84.7\%) and perform functions in health care delivery.

The QICICNS dimensionality study was performed through a factorial analysis of main components with orthogonal rotation by the varimax method and Kaiser normalization of the 33 items of the scale, in order to identify the underlying factors.The Kaiser-Meyer-Olkin test $(\mathrm{KMO}=0.95)$ and Bartlett's Sphericity Test (BST $=45,288.63 ; p<.001$ ) allowed us to confirm the factor of the correlation matrix to verify the suitability of the sample for the Factor analysis. ${ }^{[10]}$ From this analysis, the items with own value equal to or greater than the unit and the factorial loads of the items, equal to or greater than 0.50 , were retained. This index will be lower when assuming the 0.50 threshold implies deleting the item from any of the isolated factors.

Table 1 shows the results of the factorial analysis of the in- tellectual capital questionnaire and innovative capacity of the Portuguese nursing services, considering the own values, the percentage of variance explained by each factor, the variances explained, the commonalities (h2) and the total variance explained the sample adequacy measure through the KMO and BST tests and the sample adequacy measures. We also show the Cronbach's Alpha coefficients of the four constructs of the questionnaire under analysis.

From the analysis of Table 1 we assume that all items have a saturation of 0.50 , or more, and identified four constructs (or factors): Innovation (16 items), Structural Capital (10 items); Relational Capital (4 items); and Human Capital (3 items). These five factors account for $68.14 \%$ of the total variance of the scale. Factor 1 concerns to $48.28 \%$ of the total variance, the own value of 15.93 and is saturated mainly by the 16 items related to "Innovation". Factor 2 is associated with $11.55 \%$ of the total variance, the eigenvalue of 3.81 and is saturated mainly by the 10 items related to "Structural Capital". In turn, factor 3 is regards $4.63 \%$ of the total variance, the eigenvalue is 1.53 and is saturated mainly by the 4 items related to "Relational Capital". Finally, factor 4 is associated with $3.68 \%$ of the total variance, the eigenvalue of 1.22 and is saturated mainly by the 3 items related to "Human Capital".

\section{Discussion}

The results of the KMO $>6$ test and BST $<0.001$ allowed us to assure the reliability of the factorial model to this correlation matrix for the factorial analysis $(\mathrm{KMO}=0.95, \mathrm{BST}=$ $45288.63, p<.001)$. In order to evaluate the internal fidelity or consistency (precision) of the instrument, we calculated the Cronbach Alpha coefficient for each item and for the totality of the items. From the analysis of the first version of QICICNS (58 items) of the matrix of correlations between the items and the total of the scale, we can now assure that highly significant indices were obtained $(p<.001)$, except for 25 items that, besides not showing significant correlation with the total of the scale (uncorrected value), low coefficients and in some cases, values that were significant for $p<.01$ and $p<.05$, correlated negatively with other items of this instrument. Thus, it was decided for its elimination. The remaining items present significant correlations $(>0.20)$ between themselves and the total of the scale. ${ }^{[11]}$ The final version of QICICNS had 33 items.

Table 2 shows the results of the internal consistency analysis of the 33 items of QICICNS. Along with the mean and standard deviation, we describe the correlation of the item with the total of its membership scale (corrected coefficient) and the Cronbach's Alpha value of the dimension if that item was deleted. 
Table 1. Results of the exploratory factorial analysis of QICICNS

\begin{tabular}{|c|c|c|c|c|c|}
\hline \multirow{2}{*}{ Items } & \multicolumn{4}{|c|}{ Factors } & \multirow{2}{*}{ h2 } \\
\hline & 1 & 2 & 3 & 4 & \\
\hline 18. Our institution has developed and introduced many service innovations of significant relevance. & 0.57 & & & & 0.60 \\
\hline $\begin{array}{l}\text { 19. Our institution has developed and introduced many innovations of significant relevance in the service } \\
\text { production process. }\end{array}$ & 0.59 & & & & 0.63 \\
\hline $\begin{array}{l}\text { 20. The process innovations created and introduced by our institution were instrumental in reducing costs or } \\
\text { other improvements. }\end{array}$ & 0.67 & & & & 0.64 \\
\hline $\begin{array}{l}\text { 21. Our institution has developed and introduced many important management and/or administrative } \\
\text { innovations to improve financial performance. }\end{array}$ & 0.68 & & & & 0.62 \\
\hline 22. Service innovations created and introduced by our institution focus on results. & 0.80 & & & & 0.72 \\
\hline 23. Process innovations created and introduced by our institution focus on results. & 0.83 & & & & 0.76 \\
\hline 24. Management innovations created and introduced by our institution focus on results. & 0.82 & & & & 0.77 \\
\hline $\begin{array}{l}\text { 26. Our institution has adopted and introduced, from abroad, in the service processes, innovations of } \\
\text { significant relevance. }\end{array}$ & 0.79 & & & & 0.76 \\
\hline $\begin{array}{l}\text { 27. Process innovations adopted from abroad and introduced by our institution were instrumental in reducing } \\
\text { costs or other improvements. }\end{array}$ & 0.78 & & & & 0.73 \\
\hline $\begin{array}{l}\text { 28. Our institution has adopted and introduced, from abroad, management and/or administrative innovations } \\
\text { to improve financial performance. }\end{array}$ & 0.79 & & & & 0.70 \\
\hline $\begin{array}{l}\text { 29. Our institution usually adopts, from the outside (buying or assimilating), innovations, which are lately } \\
\text { applied to the institution. }\end{array}$ & 0.70 & & & & 0.60 \\
\hline $\begin{array}{l}\text { 30. Our institution adopts and introduces, from abroad, new products. Processes, management methods and } \\
\text { services. }\end{array}$ & 0.73 & & & & 0.64 \\
\hline 31. The service innovations adopted and introduced by our institution focus on results. & 0.87 & & & & 0.83 \\
\hline 32. The process innovations adopted and introduced by our institution focus on results. & 0.87 & & & & 0.84 \\
\hline 4. Our institution eases up the emergence of new ideas and the development of inventive capacity. & & 0.66 & & & 0.65 \\
\hline 5. Innovation and the attempt to change things are a basic principle of the institution. & & 0.64 & & & 0.66 \\
\hline 6. I see our institution as innovative and willing to develop new experiences. & & 0.67 & & & 0.69 \\
\hline $\begin{array}{l}\text { 7. Our institution has a working environment that enables the active participation of people in the institution's } \\
\text { innovation. }\end{array}$ & & 0.74 & & & 0.70 \\
\hline 8. Our nurses trust the people who make the strategic decisions of the institution. & & 0.74 & & & 0.61 \\
\hline 9. Our nurses trust the organization. & & 0.74 & & & 0.64 \\
\hline 10. In our institution there are improvement groups that promote innovation. & & 0.50 & & & 0.50 \\
\hline 11. Suggestions made by nurses are almost all implemented. & & 0.71 & & & 0.55 \\
\hline 12. Our institution has a set of processes and procedures focused on driving learning and innovation. & & 0.52 & & & 0.63 \\
\hline 13. There is a good system for collecting and implementing new ideas in our institution. & & 0.61 & & & 0.65 \\
\hline 14. Our institution uses collaborative networks with suppliers in order to innovate. & & & 0.72 & & 0.69 \\
\hline 15. Our institution uses collaborative networks with other competing hospitals in order to innovate. & & & 0.76 & & 0.71 \\
\hline $\begin{array}{l}\text { 16. Our institution collaborates with knowledge institutions (universities, laboratories, R \& D and others) in } \\
\text { order to innovate. }\end{array}$ & & & 0.76 & & 0.69 \\
\hline $\begin{array}{l}\text { 17. Our institution maintains (intense, continuous and structured) collaboration agreements with allies to } \\
\text { develop innovative solutions. }\end{array}$ & & & 0.75 & & 0.75 \\
\hline 1. Our leaders are adept at influencing people to volunteer and implement their initiative in order to innovate. & & & & 0.63 & 0.53 \\
\hline 2. Our leaders like change. & & & & 0.79 & 0.75 \\
\hline 3. Our leaders are keen on innovation. & & & & 0.75 & 0.77 \\
\hline Total variance explained: $68.14 \%$ & 48.28 & 11.55 & 4.63 & 3.68 & \\
\hline Own value & 15.93 & 3.81 & 1.53 & 1.22 & \\
\hline
\end{tabular}

Note. Measurement of suitability of the Kaiser-Meyer-Olkin sample: 0.95; Bartlett's Sphericity Test: 45,288.63; $p<.001$ 
Table 2. Results of QICICNS internal consistency analysis

\begin{tabular}{|c|c|c|c|c|}
\hline Items & Mean & $\begin{array}{l}\text { Standard } \\
\text { Deviation }\end{array}$ & r itc ${ }^{*}$ & $\begin{array}{l}\text { Cronbach's alpha } \\
\text { If item deleted }\end{array}$ \\
\hline \multicolumn{5}{|l|}{ Human Capital: $\alpha=0.83$} \\
\hline $\begin{array}{l}\text { 1. Our leaders are adept at influencing people to freely volunteer and implement their initiative in } \\
\text { order to innovate. }\end{array}$ & 2.28 & 1.12 & 0.47 & 0.97 \\
\hline 2. Our leaders like change. & 2.34 & 1.04 & 0.51 & 0.96 \\
\hline 3. Our leaders are keen on innovation. & 2.23 & 1.03 & 0.58 & 0.96 \\
\hline \multicolumn{5}{|l|}{ Structural Capital: $\alpha=0.93$} \\
\hline 4. Our institution promotes the emergence of new ideas and the development of inventive capacity. & 2.52 & 1.02 & 0.66 & 0.96 \\
\hline 5. Innovation and change are basic principles of the institution. & 2.49 & 1.01 & 0.68 & 0.96 \\
\hline 6. I see our institution as innovative and willing to develop new experiences. & 2.62 & 1.00 & 0.71 & 0.96 \\
\hline $\begin{array}{l}\text { 7. Our institution has a working environment that enables the active involvement of people in the } \\
\text { innovation of the institution. }\end{array}$ & 2.36 & 0.98 & 0.69 & 0.96 \\
\hline 9. Our nurses trust the organization. & 2.50 & 0.95 & 0.63 & 0.96 \\
\hline 10. In our institution there are improvement groups that promote innovation. & 2.78 & 1.05 & 0.63 & 0.96 \\
\hline 11. The majority of suggestions made by nurses are executed. & 2.14 & 0.91 & 0.54 & 0.96 \\
\hline 12. Our institution has a set of processes and procedures focused on driving learning and innovation. & 2.65 & 1.05 & 0.69 & 0.96 \\
\hline 13. There is a good system for collecting and effecting new ideas in our institution. & 2.09 & 0.90 & 0.70 & 0.96 \\
\hline \multicolumn{5}{|l|}{ Relational Capital: $\alpha=0.88$} \\
\hline 14. Our institution uses collaborative networks with its suppliers to innovate. & 2.43 & 0.92 & 0.64 & 0.96 \\
\hline 15. Our institution uses collaborative networks with other competing hospitals to innovate. & 2.45 & 0.96 & 0.60 & 0.96 \\
\hline $\begin{array}{l}\text { 16. Our institution collaborates with knowledge institutions (universities, laboratories, R \& D and } \\
\text { others) to innovate. }\end{array}$ & 2.90 & 1.06 & 0.59 & 0.96 \\
\hline $\begin{array}{l}\text { 17. Our institution maintains (intense, continuous and structured) collaboration agreements with } \\
\text { allies to develop innovative solutions. }\end{array}$ & 2.46 & 0.96 & 0.67 & 0.96 \\
\hline $\begin{array}{l}\text { 18. Our institution has developed and introduced several service innovations of significant } \\
\text { relevance. }\end{array}$ & 2.80 & 0.93 & 0.74 & 0.96 \\
\hline $\begin{array}{l}\text { 19. Our institution has developed and introduced several innovations of significant relevance in the } \\
\text { service production process. }\end{array}$ & 2.67 & 0.91 & 0.75 & 0.96 \\
\hline $\begin{array}{l}\text { 20. The process innovations created and introduced by our institution were instrumental in reducing } \\
\text { costs or other improvements. }\end{array}$ & 2.76 & 0.92 & 0.70 & 0.96 \\
\hline $\begin{array}{l}\text { 21. Our institution has developed and introduced several important management and/or } \\
\text { administrative innovations to improve financial performance. }\end{array}$ & 2.80 & 0.91 & 0.68 & 0.96 \\
\hline 22. Service innovations created and introduced by our institution focus on results. & 3.03 & 0.90 & 0.71 & 0.96 \\
\hline 23. The process innovations created and introduced by our institution focus on results. & 3.07 & 0.89 & 0.71 & 0.96 \\
\hline 24. Management innovations created and introduced by our institution focus on results. & 3.02 & 0.92 & 0.69 & 0.96 \\
\hline $\begin{array}{l}\text { 25. Our institution has adopted and introduced, from abroad, several service innovations' of } \\
\text { significant relevance. }\end{array}$ & 2.72 & 0.83 & 0.72 & 0.96 \\
\hline $\begin{array}{l}\text { 26. Our institution has adopted and introduced, from abroad, in the service processes several } \\
\text { innovations of significant relevance. }\end{array}$ & 2.68 & 0.83 & 0.76 & 0.96 \\
\hline $\begin{array}{l}\text { 27. Process innovations adopted and introduced from abroad were instrumental in reducing costs or } \\
\text { other improvements. }\end{array}$ & 2.74 & 0.85 & 0.70 & 0.96 \\
\hline $\begin{array}{l}\text { 28. Our institution has adopted and introduced from abroad several important management and/or } \\
\text { administrative innovations to improve financial performance. }\end{array}$ & 2.75 & 0.84 & 0.68 & 0.96 \\
\hline $\begin{array}{l}\text { 29. Usually our institution adopts innovations from the outside (buying or assimilating), which are } \\
\text { then apllied to the institution. }\end{array}$ & 2.73 & 0.82 & 0.67 & 0.96 \\
\hline $\begin{array}{l}\text { 30. Our institution adopts and introduces from abroad new products, processes, management } \\
\text { methods and services. }\end{array}$ & 2.80 & 0.83 & 0.70 & 0.96 \\
\hline 31. Service innovations adopted and introduced by our institution focus on results. & 2.97 & 0.87 & 0.73 & 0.96 \\
\hline 32. Process innovations adopted and introduced by our institution focus on results. & 2.96 & 0.87 & 0.74 & 0.96 \\
\hline
\end{tabular}

Note. ${ }^{*}$ Global $\alpha=0.96$ 
Table 3. Results in items by constructs of QICICNS

\begin{tabular}{lllllll}
\hline Constructs & Items n $^{\mathbf{0}}$ & $\begin{array}{l}\text { Variation of } \\
\text { means }\end{array}$ & $\begin{array}{l}\text { Variation of } \\
\text { standard deviations }\end{array}$ & $\begin{array}{l}\text { r itc } \\
\text { (corrected) }\end{array}$ & M Scale & $\begin{array}{l}\text { Cronbach } \\
\text { Aplha }\end{array}$ \\
\hline Human Capital & 3 & $2.23-2.34$ & $1.03-1.12$ & $0.56-0.76$ & 6.84 & 0.83 \\
Structural Capital & 10 & $2.09-2.78$ & $0.90-1.05$ & $0.64-0.79$ & 24.59 & 7.67 \\
Relational Capital & 4 & $2.43-2.90$ & $0.92-1.06$ & $0.71-0.77$ & 10.23 & 3.34 \\
Innovation & 16 & $2.67-3.07$ & $0.82-0.93$ & $0.71-0.86$ & 45.44 & 0.88 \\
\hline
\end{tabular}

Table 4. Correlation matrix between QICICNS constructs and total scale

\begin{tabular}{lllll}
\hline Constructs & Structural Capital & Relational Capital & Human Capital & Total Scale \\
\hline Innovation & $0.60^{* *}$ & $0.58^{* * *}$ & $0.40^{* *}$ & $0.90^{* *}$ \\
Structural Capital & & $0.66^{* *}$ & $0.63^{* *}$ & $0.87^{* *}$ \\
Relational Capital & & & $0.42^{* *}$ & $0.76^{* *}$ \\
Human Capital & & & & $0.64^{* *}$ \\
\hline
\end{tabular}

Note. ${ }^{* *} p \leq .001$

Table 5. Matrix of correlation between constructs and QICICNS items

\begin{tabular}{|c|c|c|c|c|}
\hline Items & Innovation & $\begin{array}{l}\text { Structural } \\
\text { Capital }\end{array}$ & $\begin{array}{l}\text { Relational } \\
\text { Capital }\end{array}$ & $\begin{array}{l}\text { Human } \\
\text { Capital }\end{array}$ \\
\hline Q1 & $0.31^{* * *}$ & $0.49^{* *}$ & $0.33^{* *}$ & $0.81^{* *}$ \\
\hline Q2 & $0.34^{* *}$ & $0.53^{* *}$ & $0.36^{* *}$ & $0.89^{\text {*** }}$ \\
\hline Q3 & $0.39^{* *}$ & $0.60^{* *}$ & $0.40^{* *}$ & $0.90^{* * *}$ \\
\hline Q4 & $0.46^{* *}$ & $0.81^{* *}$ & $0.50^{* *}$ & $0.53^{* *}$ \\
\hline Q5 & $0.47^{* *}$ & $0.82^{* *}$ & $0.52^{* *}$ & $0.56^{* *}$ \\
\hline Q6 & $0.50^{* *}$ & $0.83^{* *}$ & $0.55^{* *}$ & $0.56^{* *}$ \\
\hline Q7 & $0.50^{* *}$ & $0.84^{* *}$ & $0.50^{* *}$ & $0.51^{* *}$ \\
\hline Q8 & $0.41^{* *}$ & $0.73^{* *}$ & $0.43^{* *}$ & $0.44^{* *}$ \\
\hline Q9 & $0.46^{* *}$ & $0.77^{* *}$ & $0.48^{* *}$ & $0.45^{* *}$ \\
\hline Q10 & $0.47^{* *}$ & $0.73^{* *}$ & $0.53^{* *}$ & $0.43^{* *}$ \\
\hline Q11 & $0.37^{* *}$ & $0.71^{* *}$ & $0.39^{* *}$ & $0.42^{\text {*** }}$ \\
\hline Q12 & $0.51^{* *}$ & $0.77^{* *}$ & $0.63^{* *}$ & $0.46^{* *}$ \\
\hline Q13 & $0.50^{* *}$ & $0.81^{* *}$ & $0.60^{* *}$ & $0.52^{* *}$ \\
\hline Q14 & $0.50^{* *}$ & $0.59^{* *}$ & $0.84^{* *}$ & $0.39^{\text {*** }}$ \\
\hline Q15 & $0.46^{* *}$ & $0.56^{* *}$ & $0.86^{* *}$ & $0.34^{* *}$ \\
\hline Q16 & $0.48^{* *}$ & $0.51^{* *}$ & $0.85^{* *}$ & $0.32^{* *}$ \\
\hline Q17 & $0.53^{* *}$ & $0.60^{* *}$ & $0.88^{* *}$ & $0.40^{* *}$ \\
\hline Q18 & $0.75^{* *}$ & $0.59^{* *}$ & $0.54^{* *}$ & $0.41^{\text {*** }}$ \\
\hline Q19 & $0.77^{* *}$ & $0.61^{* *}$ & $0.54^{* *}$ & $0.40^{* * *}$ \\
\hline Q20 & $0.78^{* * *}$ & $0.52^{* *}$ & $0.46^{* *}$ & $0.32^{* * *}$ \\
\hline Q21 & $0.77^{* *}$ & $0.49^{* *}$ & $0.45^{* *}$ & $0.32^{* * *}$ \\
\hline Q22 & $0.83^{* *}$ & $0.46^{* *}$ & $0.47^{* *}$ & $0.32^{* *}$ \\
\hline Q23 & $0.85^{\text {** }}$ & $0.45^{* *}$ & $0.43^{* *}$ & $0.31^{\text {*** }}$ \\
\hline Q24 & $0.83^{* *}$ & $0.45^{* *}$ & $0.41^{* *}$ & $0.29^{* * *}$ \\
\hline Q25 & $0.83^{* *}$ & $0.49^{* *}$ & $0.50^{* *}$ & $0.32^{* *}$ \\
\hline Q26 & $0.87^{* *}$ & $0.52^{* *}$ & $0.52^{* *}$ & $0.33^{\text {** }}$ \\
\hline Q27 & $0.83^{* *}$ & $0.47^{* *}$ & $0.44^{* *}$ & $0.28^{* * *}$ \\
\hline Q28 & $0.82^{* *}$ & $0.44^{* *}$ & $0.43^{* *}$ & $0.29^{* *}$ \\
\hline Q29 & $0.77^{* *}$ & $0.45^{* *}$ & $0.47^{* *}$ & $0.33^{\text {*** }}$ \\
\hline Q30 & $0.79^{* *}$ & $0.46^{* *}$ & $0.48^{* *}$ & $0.34^{* *}$ \\
\hline Q31 & $0.88^{* * *}$ & $0.44^{* *}$ & $0.46^{* *}$ & $0.31^{* *}$ \\
\hline Q32 & $0.88^{* *}$ & $0.46^{* *}$ & $0.47^{* *}$ & $0.33^{\text {*** }}$ \\
\hline Q33 & $0.87^{* *}$ & $0.46^{* *}$ & $0.48^{* * *}$ & $0.33^{* *}$ \\
\hline
\end{tabular}

Analysing data of Table 2, we found that the Cronbach Alpha coefficients for each item, with the total scale (Global Alpha $=0.96$ ), oscillate between 0.96 and 0.97 , thus being in the category Internal consistency "too high". These values indicate a good correlation between all items and a good homogeneity of the items, suggesting good indices of internal consistency, distributed in 4 constructs (greater than 0.80), with Cronbach's alpha values ranging from 0.83 to 0.97 . These results show a reliable and robust instrument to study intellectual capital and the innovative capacity of nursing services in health organizations.

Table 3 sums up the items by dimension, the variations of the means and the standard deviations of the constructs and we investigate how the coefficients of correlation between the item and the subtotal of each factor contribute to the mean and standard deviation. Finally, we present the alpha coefficient values of each of the constructs.

After analysing Table 3 we may conclude that the highest average is "Innovation" (45.44), followed by "Structural Capital" $(24,59)$. Finally, the Cronbach alpha coefficient of the four constructs ranges between 0.83 and 0.97 .

Next, we wanted to check the connection between the constructs of the Intellectual Capital Questionnaire and Innovative Capacity and the Total Scale. For this analysis, we made a study of the correlations (Product-Moment or $r$ of Pearson) between these constructs, considering the global sample under study. Table 4 shows the correlation matrix.

When related to the four constructs of QICICNS with the Total Scale and considering the criteria of Pestana and Gageiro (2014), it is shown that the magnitude of the correlations 
range from moderate to high (0.40-0.90). It should be clear that the four constructs correlate with each other and with the total Scale in a statistically significant way. The dimension that best correlates with the Total Scale is the "Innovation" dimension $(r=0.90 ; p \leq .001)$.

The discriminative validity of an item is evidenced by the difference between the correlations of the item and the dimension to which it belongs, in contrast with the correlation of the item with the constructs to which it does not belong. Table 5 shows the correlation matrix between QICICNS constructs and items.

Through the analysis of the correlation between the items, individually, with each of the constructs of the scale, we are able to state that the highest correlation value is connected to the dimension to which it belongs (see Table 5). Therefore we proved that the intellectual capital of the nursing services is relevant to the innovation of Portuguese health organizations. It validates the differentiated relevance for each of the elements of intellectual capital in the innovation of Portuguese health organizations. We also checked that the relational capital and the structural capital of the nursing services directly influence the innovation (product, process, management). Human capital is the only element that is not directly related to the organization's innovation, although it has indirect influence through relational capital and structural capital. These conclusions are extremely important and should be considered along with other management tools. They definitely show us what level of organizational intervention, since, it clearly states where the organization measures are aligned in the pursuit of innovation.

\section{Conclusions}

This data analysis allows us to verify which of the components of the intellectual capital contributes to the improve- ment of the health services, since the CI has an intrinsic character to the organizations, reflecting an extra value for evaluation of the organizational factors, which require an intervention of improvement by its leaders. In fact, an evaluation of the factors of human capital, structural capital and relational capital that contributes to organizational innovation is done and for that matter to organize and plan organizational improvement interventions in each of the constructs of intellectual capital, or systemically in various constructs of intellectual capital.

The consequences of apply this questionnaire are summarized in practical contents which can contribute to the improvement of nursing services, namely diagnosing the area required for interventions and improvements, that is assessing whether it is necessary to act on the human capital of the services, according to each nurse. On the other hand, it allows us to identify the need to act in the structural capital of services, which represents the structure and culture of services (standards, protocols and procedures). Last but not least, it enables to assess the relational capital of nursing services, and whether it is directed towards the service objectives, contributing to the orientation of collaboration networks, strengthening alliances and more active participation of users in the organization's policies. The findings of our study support the QICICNS as a valid and reliable tool in instrument to support the management of the nursing services, of a strategic nature, contributing to the decision making of the nursing managers in the organizational health units.

\section{CONFlicts OF INTEREST Disclosure}

The authors declare they have no conflicts of interest.

\section{REFERENCES}

[1] Santos-Rodrigues H, Figueroa-Dorrego P, Jardón-Fernández C Model of Intellectual Capital Analysis Under the Perspective of the Incidence in the Capacity of Innovation (dissertation). Universidad de Vigo. 2008.

[2] Peng TA. Intellectual capital and performance indicators: Taiwanese healthcare sector. Journal of Intellectual Capital. 2007; 538-556 https://doi.org/10.1108/14691930710774902

[3] Mura M, Lettieri E, Spiller N. Intellectual Capital and Innovative Work Behavior: Opening the Black box. International Journal of Engineering Business Management. 2012; 4(39): 1-10.

[4] Covell CL. The middle-range theory of nursing intellectual capital. Journal of Advanced Nursing. 2008; 63(1): 94-103. PMid: 18498345 https ://doi.org/10.1111/j.1365-2648.2008.04626.x
[5] McEwen M, Willis E. Theoretical basis for nursing (4th ed.). Philadelphia, PA: Wolters Kluwer/Lippincott Williams \& Wilkins; 2014.

[6] Soares-Faria J, Santos-Rodrigues H, Morais C. The influence of intellectual capital on the innovative capacity of a hospital. Viana do Castelo: Polytechnic Institute of Viana do Castelo. 2012.

[7] Silva DO. Proposal for analysis of innovation management in hospital services: a study at the Mãe de Deus Hospital. Porto Alegre, RS. 2011.

[8] Covell CL, Sidani S. Nursing Intellectual Capital Theory: Implications for Research and practice. Online Journal of Issues in Nursing. 2013; 18(2): 2. Available from: http://nursingworld.org/M ainMenuCategories/ANAMarketplace/ANAPeriodicals/OJ IN/TableofContents/Vol-18-2013/No2-May-2013/Nursin g-Intellectual-Capital-Theory.html 
[9] Poe S. Building Nursing Intellectual Capital for Safe Use of Inform. Journal of Nursing Care Quality. 2011 Apr-Jun; 26(2): 1109. PMid: 21209593. https://doi.org/10.1097/NCQ.0b013e 31820b221d

[10] Pestana MH, Gageiro JN. Data analysis for social sciences: the complementarity of SPSS. 6th ed. Lisbon: Sílabo; 2014. Almeida LS, Freire T. Methodology of research in psychology and education. Braga: Psyquilibrios; 2008.

[11] Almeida LS, Freire T. Methodology of research in psychology and education. Braga: Psyquilibrios; 2008 